\title{
An unexpected diagnostic course of systemic lupus erythematosus
}

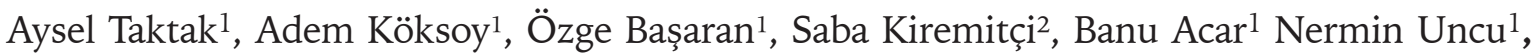 \\ Nilgün Çakar ${ }^{1}$ \\ ${ }^{1}$ Department of Pediatric Nephrology and Rheumatology, Ankara Child Health, Hematology, Oncology Training and \\ Research Hospital, ${ }^{2}$ Department of Pathology, Ankara University Faculty of Medicine. \\ E-mail: aysel.taktak@gmail.com \\ Received: 3 June 2015, Revised: 16 September 2015, Accepted: 14 October 2015
}

\begin{abstract}
SUMMARY: Taktak A, Köksoy A, Başaran Ö, Kiremitçi S, Acar B, Uncu N, Çakar N. An unexpected diagnostic course of systemic lupus erythematosus. Turk J Pediatr 2016; 58: 223-226.

Thrombotic microangiopathy (TM), especially thrombotic thrombocytopenic purpura (TTP) is described in systemic lupus erythematosus (SLE) as a severe hematological involvement. However hemolytic uremic syndrome (HUS) is seen less frequently in SLE, particularly as an initial presentation. Here we present a 15-year old boy presenting with gross hematuria, decreased urinary output and petechial lesions. He was diagnosed as atypical HUS according to the classical triad of TM, along with observation of hypocomplementemia and negative stool cultures. In addition, his symptoms fulfilled the 2012 revised criteria for the classification of SLE. He was treated with plasma infusions and methylprednisolone/prednisone. At follow up his laboratory findings and general condition improved and no relapse was seen.
\end{abstract}

Key words: systemic lupus erythematosus, thrombotic microangiopathy, child.

Hemolytic uremic syndrome (HUS) is characterized by the triad of microangiopathic anemia, thrombocytopenia and kidney injury ${ }^{1}$. HUS is classified into three categories: 1) Typical disease which occurs sporadically or epidemically due to Shiga toxin producing E. coli, 2) Familial atypical cases due to genetic abnormalities of complement regulatory proteins and 3) Sporadic atypical cases which are secondary to infections, medications, malignancy or systemic diseases such as systemic lupus erythematosus $(\mathrm{SLE})^{2}$. Thrombotic microangiopathy (TM) is common during the course of SLE especially in antiphospholipid antibody syndrome ${ }^{3}$. In SLE patients, TM is seen as a result of direct antiglobulins, antiplatelet antibodies and antiendothelial antibodies ${ }^{4}$. However atypical HUS is a rare clinical presentation of SLE 5 .

Here we present a 15-year old adolescent whose initial presentation was atypical HUS as a rare manifestation of SLE.

\section{Case Report}

A 15-year-old boy was admitted with anorexia, vomiting, gross hematuria and decreased urine output for two days. There was no history of fever, dysuria, upper respiratory tract infection or diarrhea. He was taking levothyroxine $300 \mathrm{mcg} /$ day for 3 years with the history of total thyroidectomy due to multinodular dysmorphgenetic goiter.

On physical examination, pallor petechial lesions on the cheeks, chest and lower extremities and pretibial edema were observed. His blood pressure was 130/85 mm Hg. The rest of the physical examination was unremarkable.

The initial laboratory analysis revealed: hemoglobin, $7 \mathrm{~g} / \mathrm{dl}(12.8-16 \mathrm{~g} / \mathrm{dl})$, platelet count, $5000 / \mathrm{mm}^{3}\left(150.000-450.000 / \mathrm{mm}^{3}\right)$, reticulocyte count $9.3 \%$, lactate dehydrogenase (LDH) level $2255 \mathrm{U} / 1$ (0-248 U/1), serum urea $69 \mathrm{mg} / \mathrm{dl}(11-39 \mathrm{mg} / \mathrm{dl})$, creatinine $1.22 \mathrm{mg} / \mathrm{dl}$ (0.5-1.2 mg/dl), serum proteins and electrolytes were in normal range. Peripheral blood smear showed macrocytic hypochromic anemia, anisopoikilocytosis composed of schistocytes. His direct antiglobulin (Coombs') test was 3 $(+)$. Erythrocyte sedimentation rate was 46 $\mathrm{mm} / \mathrm{h}$, C-reactive protein was $7.6 \mathrm{mg} / \mathrm{dl}(0-8$ $\mathrm{mg} / \mathrm{dl})$. 
The urine was dark brown macroscopically. Urinalysis revealed $3(+)$ proteinuria and $3(+)$ hematuria with 76 dysmorphic erythrocytes per high power field. Spot urine protein/creatinine ratio was 3.8. 24-hour urine collection revealed nephrotic range proteinuria $\left(56 \mathrm{mg} / \mathrm{m}^{2} / \mathrm{h}\right)$. The urine and blood cultures showed no growth.

Renal ultrasound revealed kidneys with normal shape and size but renal cortical echogenicity was markedly increased.

The patient had hemolytic anemia, thrombocytopenia and renal impairment, with no history of fever, dysuria, upper respiratory tract infection or diarrhea. Therefore the most likely diagnosis was atypical HUS or less likely thrombotic thrombocytopenic purpura (TTP).

For differential diagnosis serum complement level 3 (C3), ADAMTS13 activities, and antiADAMTS13 antibody was performed. His C3 level was $54 \mathrm{mg} / \mathrm{dl}$ (83-177 mg/dl). ADAMTS13 activity was $98 \%$ and anti-ADAMTS13 antibody was $6.4 \mathrm{U} / \mathrm{mL}$ (normal $<15 \mathrm{U} / \mathrm{ml}$ ). However HUS could not explain the positive direct Coombs' test result, therefore auto antibodies such as antinuclear antibody (ANA), anti-double stranded (ds) DNA antibodies, anti-cardiolipin and anti-phospholipid antibodies were tested. ANA was $3(+)$, anti-ds DNA antibody was $666.5 \mathrm{IU} / \mathrm{ml}(0-200 \mathrm{IU} / \mathrm{ml})$, anti-cardiolipin and anti-phospholipid antibodies were negative. Echocardiography revealed minimal pericardial effusion. These symptoms and findings met the Systemic Lupus International Collaborating Clinics criteria, 2012 (SLICC) $^{6}$, he was also diagnosed as SLE.

The cause of proteinuria may both be due to lupus nephritis and hemolytic uremic syndrome. Percutaneous renal biopsy was performed with the thrombocyte count of $147.000 / \mathrm{mm}^{3}$. Light microscopic examination of the renal biopsy revealed diffuse moderate glomerular mesangial hypercellularity with mesangial widening and glomerular capillary thrombosis in one glomeruli (Fig. 1). The immunofluorescence study showed "full house" immunoglobulin deposition (IgG, IgA, IgM) together with diffuse $\mathrm{C} 3$ and $\mathrm{C} 1 \mathrm{q}$ deposition in glomerular mesangial areas (Fig. 2). Histopathologic examination was consistent with lupus nephritis (Class II of the International Society of Nephrology/Renal Pathology Society 2003) and HUS.
Fresh frozen plasma was initiated at $10 \mathrm{ml} /$ $\mathrm{kg}$ twice a day. Methylprednisolone pulses (30 $\mathrm{mg} / \mathrm{kg} /$ dose, maximum $1 \mathrm{~g}$ ) were initiated on the second day given for five days consecutively, followed by oral prednisone $(2 \mathrm{mg} / \mathrm{kg} /$ day $)$, hydroxychloroquine $(5 \mathrm{mg} / \mathrm{kg} /$ day $)$ and enalapril $(0.1 \mathrm{mg} / \mathrm{kg} /$ day $)$. After the first month of treatment, oral steroid was tapered gradually. At the end of six months, the prednisone dose was $20 \mathrm{mg} /$ day .His laboratory examination was as follows: 24-hour urine protein excretion $7.6 \mathrm{mg} / \mathrm{m}^{2} / \mathrm{h}$, urea $30 \mathrm{mg} / \mathrm{dl}$, creatinine 0.65 $\mathrm{mg} / \mathrm{dl}$, hemoglobin $13 \mathrm{~g} / \mathrm{dl}$, platelet count $258000 / \mathrm{mm}^{3}$, C3 level was $94 \mathrm{mg} / \mathrm{dl}$. He had no relapse during follow up.

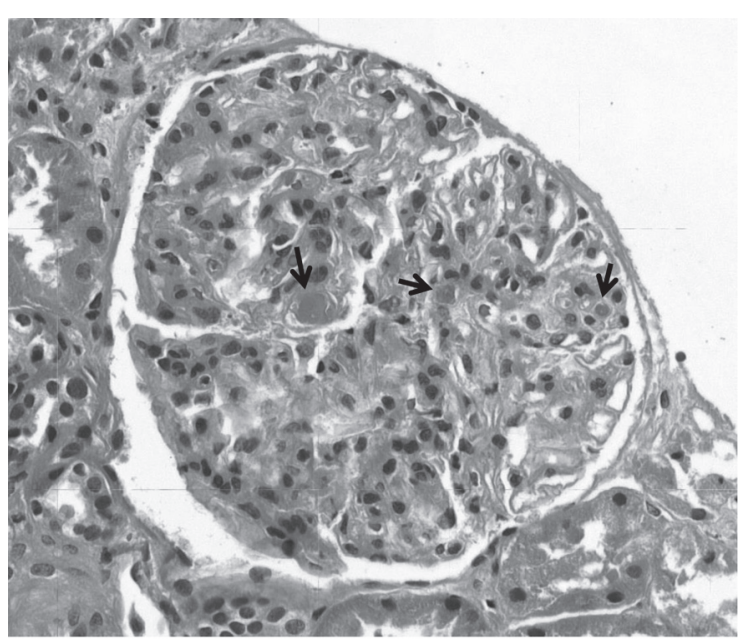

Fig. 1. The glomerulus displays a moderate mesangial hypercellularity, and glomerular capillary thrombosis is seen in a few capillary loops (arrows). Hematoxylin-Eosin x400

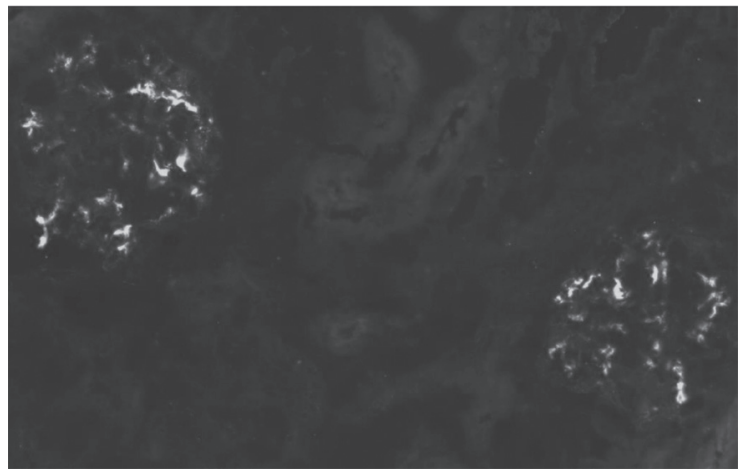

Fig. 2. The immunofluorescence showed diffuse strong glomerular $\mathrm{Clq}$ staining in the mesangial regions. 


\section{Discussion}

Systemic lupus erythematosus is an autoimmune disease characterized by the production of wide spread autoantibodies which leads to immune complex deposition, inflammation or organ damage. It may affect many organs and may cause various clinical features such as skin rash, arthritis, serositis and involvement of the kidney, lung, central nervous system and hematologic system ${ }^{7}$.

Thrombotic microangiopathy in SLE may result from TTP and less frequently from HUS or rarely from a direct endothelial injury triggered by anti-endothelial antibodies, malignant hypertension or calcineurin inhibitorassociated ${ }^{4}$. In TM, cytopenias are mediated by mechanical hemolysis revealed by schistocytes, whereas in SLE, an autoimmune process is involved, revealed by positive tests for direct antiglobulin and anti-platelet antibodies ${ }^{3}$.

A major feature of SLE is the formation of immune complexes. These immune complexes trigger the complement system and lead to activation of the classical pathway with $\mathrm{C} 4 \mathrm{~b}$ and $\mathrm{C} 3 \mathrm{~b}$ deposition which can covalently bind to glomerular endothelial surfaces and basement membranes through the thiol ester site, mounting of the membrane attack complex (C5b-9), release of C3a and C5a anaphylatoxins and commonly causing cellular injury and tissue inflammation. Complement is consumed in active SLE, resulting in hypocomplementemia (typically low C4 and C3) 8,9.

Atypical HUS is one of the diseases causing TM. Atypical HUS manifests as a microangiopathic disease with mechanical anemia, thrombocytopenia and acute renal failure. The clear link between aHUS and the complement pathway is well recognized. Mutations have been identified in factor $\mathrm{H}$, MCP, factor I and thrombomodulin (THBD). These proteins act as regulating factors of the C3 convertase. The rate of activation of the alternative pathway outstrips the rate of downstream regulatory processes on endothelial cells leading to their injury. Low C3 is seen in/or less than $50 \%$ of the patients. Therefore C3 antigen measurement is not an adequate screening test for aHUS because a normal result does not rule out a function altering mutation and the same conclusion can be applied to factors $\mathrm{H}, \mathrm{I}$, and $\mathrm{B}^{10}$.
Complement consumption is seen during SLE flares, which could lead to endothelial activation, as observed in congenital HUS. This phenomenon might explain one of the links between lupus nephritis and HUS. Furthermore, it has been shown that some non-shiga toxinassociated HUS are not caused by mutations of regulatory proteins of the complement alternative pathway like $\mathrm{FH}$ and cofactor protein (CD46), but occur in the context of an autoimmune disease with the development of anti-factor $\mathrm{H}$ antibodies leading to an acquired factor $\mathrm{H}$ deficiency ${ }^{11}$.

Although no significant difference in the presence of fever, neurological disorder, anemia and negative Coombs' test was noticed between lupus patients with and without $\mathrm{TM}$, the clinical evidence of microangiopathic hemolytic anemia (MAHA) such as elevated $\mathrm{LDH}$ and the presence of increased peripheral schistocytes may be helpful in identifying TTP-HUS clinically in patients with lupus nephritis. Renal histopathology could provide solid evidence of $\mathrm{TM}^{12}$.

In our case, there was no history of bloody diarrhea, stool culture was negative, LDH was increased, C3 level was decreased, peripheral schistocytes was increased, ADAMTS 13 and anti-ADAMTS13 antibody levels were in normal range, and therefore aHUS was primarily thought. Factor $\mathrm{H}$ antibody could not be measured. As direct Coombs' test was positive, viral serologic tests and auto antibodies were performed. According to ANA and anti-ds DNA positivity, serositis and renal histopathologic and immunoflouresan findings, he has been diagnosed as SLE based on the SLICC criteria ${ }^{6}$. Although there is a high prevalence of thyroid nodules in SLE patients, our case had histopathologically proven multinodular dysmorphgenetic goiter and his autoimmune thyroid markers were negative (anti thyroid peroxidase antibody was $7.2 \mathrm{IU} / \mathrm{ml}(0-9)$ and anti-thyroglobulin was 0.1 $\mathrm{IU} / \mathrm{ml}(0-4)$ ), which is not relevant to $\mathrm{SLE}^{13}$.

Treatment options include plasma infusion or plasma exchange within 24 hours of diagnosis and immunosuppressive medications; although there is no well established guideline for treatment of HUS in patients with lupus nephritis ${ }^{12}$. Our patient achieved clinical remission of both lupus nephritis and 
thrombotic microangiopathy after plasma therapy and immunosuppressive treatment.

In conclusion, in a patient presenting with hemolytic anemia, examination of the peripheral blood smear is very important for early diagnosis of TM. SLE should be suspected in all TM patients because of overlapping clinical and biological manifestations, such as hemolytic anemia, thrombocytopenia and renal impairment.

\section{REFERENCES}

1. Gasser C, Gautier E, Steck A, Siebenmann RE, Oechslin R. Hemolytic-uremic syndrome: bilaterale necrosis of the renal cortex in acquired hemolytic anemia. Schweiz Med Wochenschr 1955; 85: 905-909.

2. Trachtman H. HUS and TTP in children. Pediatr Clin North Am 2013; 60: 1513-1526.

3. Coppo P, Bengoufa D, Veyradier A, et al. Severe ADAMTS13 deficiency in adult idiopathic thrombotic microangiopathies defines a subset of patients characterized by various autoimmune manifestations, lower platelet count, and mild renal involvement. Medicine (Baltimore) 2004; 83: 233-244.

4. Veyradier A, Obert B, Houllier A, Meyer D, Girma JP. Specific von Willebrand factor-cleaving protease in thrombotic microangiopathies: a study of 111 cases. Blood 2001; 98: 1765-1772.

5. Kawasaki Y, Suzuki J, Nozawa R, Suzuki S, Suzuki H. A 12-year-old girl with hemolytic uremic syndrome as initial symptom of systemic lupus erythematosus and a literature review. Am J Nephrol 2002; 22: 576-580.
6. Petri M, Orbai AM, Alarcón GS, et al. Derivation and validation of Systemic Lupus International Collaborating Clinics classification criteria for systemic lupus erythematosus. Arthritis Rheum 2012; 64: 2677-2686.

7. Levy DM, Kamphuis S. Systemic lupus erythematosus in children and adolescents. Pediatr Clin North Am 2012; 59: 345-364.

8. Valentijn RM, van Overhagen $\mathrm{H}$, Hazevoet $\mathrm{HM}$, et al. The value of complement and immune complex determinations in monitoring disease activity in patients with systemic lupus erythematosus. Arthritis Rheum 1985; 28: 904-913.

9. Song $\mathrm{D}, \mathrm{Wu} \mathrm{LH}$, Wang FM, et al. The spectrum of renal thrombotic microangiopathy in lupus nephritis. Arthritis Res Ther 2013; 15: R12.

10. Goicoechea de Jorge E, Harris CL, Esparza-Gordillo $\mathrm{J}$, et al. Gain-of-function mutations in complement factor B are associated with atypical hemolytic uremic syndrome. Proc Natl Acad Sci USA 2007; 104: 240245.

11. Dragon-Durey MA, Loirat C, Cloarec S, et al. Anti-factor $\mathrm{H}$ autoantibodies associated with atypical hemolytic uremic syndrome. J Am Soc Nephrol 2005; 16: 555563.

12. Yu F, Tan Y, Zhao MH. Lupus nephritis combined with renal injury due to thrombotic thrombocytopenic purpura-hemolytic uremic syndrome. Nephrol Dial Transplant 2010; 25: 145-152.

13. Quintanilla-Flores DL, Hernadez-Coria MI, ElizondoRiojas G, Galarza-Delgado DA, Gonzalez-Gonzalez J, Tamez-Perez HE. Thyroid nodules in Hispanic patients with systemic lupus erythematosus. Lupus 2013; 22: 1509-1513. 